\title{
Parental perceptions of dental health and need for treatment in children with epilepsy: a multicenter cross-sectional study
}

This article was published in the following Dove Press journal: Pediatric Health, Medicine and Therapeutics

\author{
Ahmed Hussein Subki' \\ Abdel Moniem Mukhtar ${ }^{2}$ \\ Omar M Saggaf' \\ Ragaa $\mathrm{A} \mathrm{Ali}^{3}$ \\ Khalid A Khalifa ${ }^{3}$ \\ Dalia M Al-Lulu ${ }^{3}$ \\ Mohammed Saad Alsallum \\ Diyaa H Bokhary' \\ Ayman M Baabdullah' \\ Sulaiman M Kassar' \\ Basil M Jan ${ }^{4}$ \\ Muhab $M$ Hindi' $^{\prime}$ \\ Mohammed M Jan' \\ 'Department of Pediatrics, Faculty of \\ Medicine, King Abdulaziz University, \\ Jeddah, Saudi Arabia; ${ }^{2}$ Department \\ of Family and Community Medicine, \\ Faculty of Medicine, King Abdulaziz \\ University, Jeddah, Saudi Arabia; \\ ${ }^{3}$ Batterjee Medical College, Jeddah, \\ Saudi Arabia; ${ }^{4}$ Faculty of Dentistry, \\ King Abdulaziz University, Jeddah, \\ Saudi Arabia
}

Correspondence: Ahmed Hussein Subki Department of Pediatrics, Faculty of Medicine, King Abdulaziz University, PO Box 18924, Jeddah 21425, Saudi Arabia Tel +966560662735

Email ahs.subki@gmail.com
Background: Epilepsy is a common neurological disorder in childhood. However, there have been limited studies on its impact on the oral health of affected children. Our study aimed to assess the oral health of children with epilepsy in the city of Jeddah, Saudi Arabia, as perceived by their mothers.

Methods: We conducted a cross-sectional study in three hospitals. We included children 2-18 years old with physician-confirmed epilepsy diagnosis. We assessed parental perception of dental status and need for dental care using a standardized questionnaire that was completed by the mothers. To adjust for potential confounding variables, we used univariate and multivariate logistic regression.

Results: We included 96 children with epilepsy in our study. Their mean age was $6.4 \pm 3.4$ years. In $55.2 \%(n=53)$, dental status was rated as bad, and in $84.4 \%(n=81)$ a need for dental care was expressed. Cerebral palsy (OR 5.06, 95\% CI 1.28-19.99; $P=0.021$ ), motor disability (OR $6.41,95 \%$ CI 1.12-36.73; $P=0.037)$, referral from a pediatric neurology clinic to a dentist (OR $10.755,95 \%$ CI $3.290-35.151 ; P<0.001$ ), and irregular brushing of teeth (OR 5.397, 95\% CI 1.536-18.961; $P=0.009$ ) were significantly associated with increased risk of perceived bad dental status. Perception of the child as being overweight (OR $0.117,95 \%$ CI $0.034-0.400 ; P=0.001$ ) was significantly associated with decreased risk of perceived bad dental status. Motor disability (OR 5.73, 95\% CI 1.64-20.04; $P=0.006$ ) was significantly associated with increased parental expression of need for dental care.

Conclusion: In most children with epilepsy, perceived dental status was bad and there was a high expressed need for dental care. Interventions to improve the dental health of children with epilepsy should focus on those with cerebral palsy and motor disability.

Keywords: oral, dental, teeth, hygiene, health, epilepsy, child

\section{Introduction}

Epilepsy is a neurological disorder characterized by recurrent unprovoked seizures commonly seen in childhood. ${ }^{1}$ It is associated with numerous neurocognitive comorbidities, such as learning disabilities, developmental delay, and mental retardation..$^{2-4}$ Good oral health is important for the general health of children, especially in children with epilepsy. Nevertheless, there have not been many studies to assess the oral health or the need for dental care in children with epilepsy. Children with epilepsy experience higher rates of caries. ${ }^{5}$ Furthermore, individuals with epilepsy are less likely to use dental services, despite having higher rates of hospitalization and consultation with physicians compared to the general population. ${ }^{6}$ Interestingly, Percival et $\mathrm{al}^{7}$ found that children with epilepsy had more plaque on permanent teeth, more gingivitis, and 
more anterior-tooth trauma, yet fewer dental caries compared to controls. Another study reported that children with epilepsy were at increased risk of developing dental caries and gingival diseases compared to a control group. ${ }^{8}$ It has been documented that gingival overgrowth is a common side effect of antiepileptic drugs in childhood..$^{9,10}$ In Saudi Arabia, to our knowledge, there have been no studies assessing dental health in children with epilepsy.

Some children with epilepsy have associated motor, coordination, or cognitive difficulties resulting from the underlying cause of their seizures, such as cerebral palsy (CP). ${ }^{11}$ In others, such difficulties may be the result of their seizure type, frequency, or medication. These difficulties could contribute to the development of dental problems, such as trauma, or poor oral hygiene. ${ }^{12}$ Poor oral hygiene can create significant morbidity, and affects the well-being of these children and negatively impacts their quality of life. ${ }^{9}$ Screening for these conditions should be part of the initial assessment. The objective of this article is to present an overview of parents' perceptions of dental health issues in children with epilepsy in Saudi Arabia and outline important preventive and practical strategies for the management of this common comorbidity.

\section{Methods}

A hospital-based cross-sectional study was conducted between September 2016 and March 2017. Subjects were recruited from three main hospitals in Jeddah city, located in the western region of Saudi Arabia: King Abdulaziz University Hospital, Al-Aziziyah Maternity and Children's Hospital (AMCH), and Jeddah Maternity and Children's Hospital (JMCH). King Abdulaziz is the biggest university hospital in the western region of Saudi Arabia, while Aziziyah and Jeddah are the only maternity hospitals in Jeddah, run by the Saudi Ministry of Health. Eligibility criteria were children 2-18 years old with physician-confirmed epilepsy diagnosed more than 6 months prior to participating in our study. The mother must have been taking care of the child for at least the past 6 months.

We created a 20-item focused questionnaire to assess dental status and need for dental care as perceived by the mother. The questionnaire included questions relating to the following: history of drop attacks; considered as overweight by parents; history of vomiting or gastroesophageal reflux disease, motor disability, or cognitive disability; frequency of brushing teeth; recently been to a dentist; type of antiepileptic dug used; cause of epileptic seizure; and if there had been a referral to a dentist from the pediatric neurology clinic. The focused questionnaire also included demographics questions: the child's age, sex, and nationality, mother's and father's age, education, and employment, and total family income. To reduce selection bias, we recruited a consecutive sample of eligible children. With the purpose of reducing information bias, we measured our primary outcome, impact of epilepsy on child's and family life, using a validated and pretested questionnaire. This study was approved by the Institutional Review Board of King Abdulaziz University Hospital and the Research Ethics Committee of King Abdulaziz University in Jeddah. Signed informed consent was obtained from all subjects who participated in this study.

To describe our study population, we used frequencies and absolute numbers for categorical variables, and means, SD, medians, and interquartile ranges for continuous variables. For statistical analysis, age (of children and parents) was grouped into categories. Associations between two categorical variables were assessed using the $\chi^{2}$ test. To adjust for potential confounding variables, univariate and multivariate logistic regression models were conducted. A backwardelimination procedure was used to select variables for the regression model. For all statistical tests, $P<0.05$ was defined as the level of significance, to adjust for multiple testing. We used SPSS version 20 for data analysis.

\section{Results}

We recruited 96 children with epilepsy. The rate of refusal to participate was $<5 \%$ in all study hospitals. Table 1 lists demographic characteristics of the children, and Table 2 responses about dental status, perceived need for dental care, and risk factors. The mean age of the children was 6.4 years (SD 3.4, median 5.5). The mean age of mothers was 36 years (SD 6.3, median 36.0) and of the fathers 42 years (SD 6.9, median 40.0). Forty-nine percent of the children were female and 53.1\% Saudi. More than half (54.2\%) had a monthly family income of $<$ SR5,000 and only $8.3 \%$ $>$ SR10,000 Saudi Riyals.

Most of the parents (92.7\%) did not know the type of seizures that their child had, and only 5.2\% reported wholebody seizures. About two-thirds of children (65.6\%) suffered from CP, and in $13.5 \%$ the cause of epilepsy was unknown. The most common single antiepileptic therapy was sodium valproate $(26 \% ; n=27)$. The most common combination-antiepileptic therapy was carbamazepine with sodium valproate (42.7\%; $n=41)$. Cognitive and motor disability were equally reported in $75.0 \%$ of the cases. More than half $(53.2 \%)$ the children did not brush their teeth regularly. Two-thirds of the children had seen a dentist previously, and 64.6\% were referred to a dentist from the neuropediatric clinic. Mothers 
Table I Characteristics of children $(n=96)$

\begin{tabular}{|l|l|}
\hline & $\%(\mathbf{n})$ \\
\hline Age (years) & \\
\hline $5-10$ & $35.4(34)$ \\
$\geq 10$ & $44.8(43)$ \\
\hline Sex & $19.8(19)$ \\
Male & \\
Female & $51.0(49)$ \\
\hline Nationality & $49.0(47)$ \\
Saudi & \\
Egyptian & $53.1(51)$ \\
Syrian & $7.3(7)$ \\
Somali & $13.5(13)$ \\
Yemeni & $7.3(7)$ \\
Other & $7.3(7)$ \\
\hline Type of seizures & $11.5(11)$ \\
Do not know & \\
Whole body & $92.7(89)$ \\
Partial & $5.2(5)$ \\
\hline Cause of epilepsy & $2.1(2)$ \\
Cerebral palsy & \\
Hypoxic ischemic encephalopathy & $65.6(63)$ \\
Unknown & $5.2(5)$ \\
Other & $13.5(13)$ \\
\hline Antiepileptic drugs & $15.6(15)$ \\
Single therapy & \\
Combined therapy & $55.2(53)$ \\
\hline & $44.8(43)$ \\
\hline
\end{tabular}

reported that their children's teeth were bad in more than half the cases $(55.2 \%)$, and the majority $(84.4 \%)$ expressed the need for dental care.

\section{Parental reporting of dental status}

There was no statistically significant association between child's age, sex, or nationality and perceived dental status (Table 3). Underlying diagnosis was, however, associated with reported dental status $(P=0.002)$.

There was a statistically significant correlation between dental status reporting and both mother's $(P=0.042)$ and father's $(P=0.041)$ level of education and father's employment $(P=0.038)$. There was no statistical significance with the other variables (Table 4).

There was a statistically significant association between all the other risk factors (drop attacks, cognitive disability, motor disability, vomiting, perceived to be overweight, previous dental review, or referral to a dentist) and perceived dental status (Table 5).

\section{Parental reporting of need for dental care}

There was no statistically significant association between any of the child's demographics (age, sex, nationality, or
Table 2 Dental status and other factors

\begin{tabular}{|l|l|}
\hline & $\%(\mathbf{n})$ \\
\hline Cognitive disability & \\
No & $25.0(24)$ \\
Yes & $75.0(72)$ \\
\hline Motor disability & \\
No & $25.0(24)$ \\
Yes & $75.0(72)$ \\
\hline Dental status & \\
Good & $44.8(43)$ \\
Bad & $55.2(53)$ \\
\hline Need for dental care & \\
Needed & $84.4(81)$ \\
Not needed & $15.6(15)$ \\
\hline History of drop attacks & \\
No & $83.3(80)$ \\
Yes & $16.7(16)$ \\
\hline Brushing teeth & \\
Every day & $46.9(45)$ \\
Sometimes & $46.9(45)$ \\
Never & $6.3(6)$ \\
\hline Vomiting & \\
No & $20.8(20)$ \\
Yes & $79.2(76)$ \\
\hline Recently seen a dentist & $33.3(32)$ \\
No & $66.7(64)$ \\
Yes & $63.5(61)$ \\
\hline Perceived to be overweight & $36.5(35)$ \\
\hline No & $35.4(34)$ \\
Yes & $64.6(62)$ \\
\hline Referral to dentist after being seen in clinic \\
No & \\
Yes & \\
\hline & \\
\hline
\end{tabular}

drug therapy) and perceived need for dental care, with the exception of the underlying diagnosis ( $P=0.013$; Table 3 ). The only statistically significant association between perceived need for dental care and family demographics was that of the father's education $(P=0.026)$ (Table 4). The correlation between reported need for dental care and all the other risk factors (Table 5) was statistically significant, with the exception of drop attacks $(P=0.059)$. Particularly strong was the statistical significance of motor disability $(P=0.006)$, vomiting $(P=0.007)$, perceived to be overweight $(P<0.001)$, having previously seen a dentist $(P<0.001)$, and having received a dental referral after attending the clinic $(P<0.001)$.

\section{Univariate and multivariate analyses for perceived dental status}

The following factors were significantly associated with increased risk of reported bad teeth (univariate analysis): $\mathrm{CP}$ (OR 6.18, 95\% CI 2.42-15.75; $P<0.001$ ), motor disability (OR 7.60, 95\% CI 2.53-22.84; $P<0.001$ ), cognitive disability 
Table 3 Analysis of demographics with perceived dental status and need for dental care

\begin{tabular}{|c|c|c|c|c|c|c|}
\hline & \multicolumn{2}{|l|}{ Dental status } & \multirow[b]{2}{*}{$P$-value } & \multicolumn{2}{|l|}{ Dental care } & \multirow[t]{2}{*}{$P$-value } \\
\hline & Good, \% (n) & Bad, \% (n) & & Not needed, \% (n) & Needed, \% (n) & \\
\hline $\begin{array}{l}\text { Age } \\
<5.5 \text { years } \\
\geq 5.5 \text { years }\end{array}$ & $\begin{array}{l}39.6(19) \\
50.0(24)\end{array}$ & $\begin{array}{l}60.4(29) \\
50.0(24)\end{array}$ & 0.412 & $\begin{array}{l}20.8(10) \\
10.4(5)\end{array}$ & $\begin{array}{l}79.2(38) \\
89.6(43)\end{array}$ & 0.16 \\
\hline $\begin{array}{l}\text { Sex } \\
\text { Male } \\
\text { Female }\end{array}$ & $\begin{array}{l}44.9(22) \\
44.7(21)\end{array}$ & $\begin{array}{l}55.1(27) \\
55.3(26)\end{array}$ & 0.983 & $\begin{array}{l}16.3(8) \\
14.9(7)\end{array}$ & $\begin{array}{l}83.7(4 I) \\
85 . I(40)\end{array}$ & \\
\hline $\begin{array}{l}\text { Nationality } \\
\text { Saudi } \\
\text { Non-Saudi }\end{array}$ & $\begin{array}{l}41.2(2 I) \\
48.9(22)\end{array}$ & $\begin{array}{l}58.8(30) \\
51.1(23)\end{array}$ & 0.448 & $\begin{array}{l}15.7(8) \\
15.6(7)\end{array}$ & $\begin{array}{l}84.3(43) \\
84.4(38)\end{array}$ & 0.986 \\
\hline $\begin{array}{l}\text { Diagnosis } \\
\text { Cerebral palsy } \\
\text { Hypoxic ischemic encephalopathy } \\
\text { Unknown } \\
\text { Others }\end{array}$ & $\begin{array}{l}33.8(24) \\
60.0(3) \\
100.0(5) \\
73.3(11)\end{array}$ & $\begin{array}{l}66.2(47) \\
40.0(2) \\
0.0(0) \\
26.7(4)\end{array}$ & 0.002 & $\begin{array}{l}9.9(7) \\
20.0(1) \\
60.0(3) \\
26.7(4)\end{array}$ & $\begin{array}{l}90.1(64) \\
80.0(4) \\
40.0(2) \\
73.3(11)\end{array}$ & 0.013 \\
\hline $\begin{array}{l}\text { Antiepileptic drugs } \\
\text { Single therapy } \\
\text { Combined therapy }\end{array}$ & $\begin{array}{l}37.7(20) \\
53.5(23)\end{array}$ & $\begin{array}{l}62.3(33) \\
46.5(20)\end{array}$ & 0.123 & $\begin{array}{l}15.1(8) \\
16.3(7)\end{array}$ & $\begin{array}{l}84.9(45) \\
83.7(36)\end{array}$ & 0.874 \\
\hline
\end{tabular}

Table 4 Analysis of family demographics with perceived dental status and need for dental care

\begin{tabular}{|c|c|c|c|c|c|c|}
\hline & \multicolumn{2}{|l|}{ Dental status } & \multirow[t]{2}{*}{$P$-value } & \multicolumn{2}{|l|}{ Dental care } & \multirow[t]{2}{*}{$P$-value } \\
\hline & Good, \% (n) & Bad, \% (n) & & Not needed, \% (n) & Needed, \% (n) & \\
\hline $\begin{array}{l}\text { Mother's education } \\
\text { Below secondary } \\
\text { Secondary } \\
\text { University }\end{array}$ & $\begin{array}{l}73.3(11) \\
35.7(15) \\
43.6(17)\end{array}$ & $\begin{array}{l}26.7(4) \\
64.3(27) \\
56.4(22) \\
\end{array}$ & 0.042 & $\begin{array}{l}33.3(5) \\
9.5(4) \\
15.4(6)\end{array}$ & $\begin{array}{l}66.7(10) \\
90.5(38) \\
84.6(33)\end{array}$ & 0.093 \\
\hline $\begin{array}{l}\text { Mother's job } \\
\text { Housewife } \\
\text { Employed }\end{array}$ & $\begin{array}{l}45.5(40) \\
37.5(3)\end{array}$ & $\begin{array}{l}54.5(48) \\
62.5(5) \\
\end{array}$ & 0.665 & $\begin{array}{l}17.0(15) \\
0.0(0)\end{array}$ & $\begin{array}{l}83.0(73) \\
100.0(8)\end{array}$ & 0.204 \\
\hline $\begin{array}{l}\text { Mother's age } \\
\leq 35 \text { years } \\
>35 \text { years } \\
\end{array}$ & $\begin{array}{l}47.8(22) \\
42.0(21) \\
\end{array}$ & $\begin{array}{l}52.2(24) \\
58.0(29) \\
\end{array}$ & 0.566 & $\begin{array}{l}19.6(9) \\
12.0(6)\end{array}$ & $\begin{array}{l}80.4(37) \\
88.0(44) \\
\end{array}$ & 0.308 \\
\hline $\begin{array}{l}\text { Father's age } \\
>40 \text { years } \\
\leq 40 \text { years }\end{array}$ & $\begin{array}{l}47.2(17) \\
43.3(26)\end{array}$ & $\begin{array}{l}52.8(19) \\
56.7(34)\end{array}$ & $0.7 I I$ & $\begin{array}{l}16.7(6) \\
15.0(9)\end{array}$ & $\begin{array}{l}83.3(30) \\
85.0(51)\end{array}$ & 0.828 \\
\hline $\begin{array}{l}\text { Father's job } \\
\text { Unemployed } \\
\text { Blue-collar } \\
\text { White-collar }\end{array}$ & $\begin{array}{l}21.7(5) \\
52.9(18) \\
51.3(20)\end{array}$ & $\begin{array}{l}78.3(18) \\
47.1(16) \\
48.7(19)\end{array}$ & 0.038 & $\begin{array}{l}17.4(4) \\
14.7(5) \\
15.4(6)\end{array}$ & $\begin{array}{l}82.6(19) \\
85.3(29) \\
84.6(33)\end{array}$ & 0.962 \\
\hline $\begin{array}{l}\text { Father's education } \\
\text { Below secondary } \\
\text { Secondary } \\
\text { University }\end{array}$ & $\begin{array}{l}76.9(10) \\
37.5(12) \\
41.2(21)\end{array}$ & $\begin{array}{l}23.1(3) \\
62.5(20) \\
58.8(30)\end{array}$ & 0.041 & $\begin{array}{l}38.5(5) \\
6.3(2) \\
15.7(8)\end{array}$ & $\begin{array}{l}61.5(8) \\
93.8(30) \\
84.3(43)\end{array}$ & 0.026 \\
\hline $\begin{array}{l}\text { Income (in Saudi } \\
\text { Riyal [SR]) } \\
\text { SR }<5,000 \\
\text { SR } 5,000-10,000 \\
\text { SR }>10,000\end{array}$ & $\begin{array}{l}50.0(26) \\
38.9(14) \\
37.5(3)\end{array}$ & $\begin{array}{l}50.0(26) \\
61.1(22) \\
62.5(5)\end{array}$ & 0.535 & $\begin{array}{l}17.3(9) \\
13.9(5) \\
12.5(1)\end{array}$ & $\begin{array}{l}82.7(43) \\
86.1(31) \\
87.5(7)\end{array}$ & 0.881 \\
\hline
\end{tabular}

(OR 5.64, 95\% CI 1.99-16.01; $P=0.001$ ), previous visit to the dentist (OR 7.477; CI 2.914-19.185; $P<0.001$ ), and receipt of dental appointment (referral) after coming to neuropediatric clinic (OR 11.089, CI 4.050-30.365; $P<0.001)$ In contrast, drop attack (OR 0.303, 95\% CI 0.096-0.955; $P=0.04$ ) and perception of child being overweight by parent (OR 0.134, $95 \%$ CI $0.052-0.343 ; P<0.001)$ were significantly associated with decreased risk of bad teeth.

Multivariate analysis revealed statistically significant association between increased reports of bad teeth and 
Table 5 Analysis of other risk factors with perceived dental status and need for dental care

\begin{tabular}{|c|c|c|c|c|c|c|}
\hline & \multicolumn{2}{|c|}{ Dental status } & \multirow[t]{2}{*}{$P$-value } & \multicolumn{2}{|l|}{ Dental care } & \multirow[t]{2}{*}{$P$-value } \\
\hline & Good, \% (n) & Bad, \% (n) & & Not needed, \% (n) & Needed, \% (n) & \\
\hline \multicolumn{7}{|c|}{ Drop attack } \\
\hline No & $40.0(32)$ & $60.0(48)$ & 0.035 & $12.5(10)$ & $87.5(70)$ & 0.059 \\
\hline Yes & $68.8(\mathrm{II})$ & $31.3(5)$ & & $31.3(5)$ & $68.8(\mathrm{II})$ & \\
\hline \multicolumn{7}{|c|}{ Cognitive disability } \\
\hline No & $75.0(18)$ & $25.0(6)$ & 0.001 & $29.2(7)$ & $70.8(17)$ & 0.035 \\
\hline Yes & $34.7(25)$ & $65.3(47)$ & & II.I (8) & $88.9(64)$ & \\
\hline \multicolumn{7}{|c|}{ Motor disability } \\
\hline No & $79.2(19)$ & $20.8(5)$ & $<0.001$ & $33.3(8)$ & $66.7(16)$ & 0.006 \\
\hline Yes & $33.3(24)$ & $66.7(48)$ & & $9.7(7)$ & $90.3(65)$ & \\
\hline \multicolumn{7}{|l|}{ Vomiting } \\
\hline No & $65.0(13)$ & $35.0(7)$ & 0.041 & $35.0(7)$ & $65.0(13)$ & 0.007 \\
\hline Yes & $39.5(30)$ & $60.5(46)$ & & $10.5(8)$ & $89.5(68)$ & \\
\hline \multicolumn{7}{|c|}{ Perceived to be overweight } \\
\hline Yes & $74.3(26)$ & $25.7(9)$ & $<0.001$ & $3.3(2)$ & $96.7(59)$ & $<0.001$ \\
\hline No & $27.9(17)$ & $72.1(44)$ & & $37.1(13)$ & $62.9(22)$ & \\
\hline \multicolumn{7}{|c|}{ Recently seen a dentist } \\
\hline Yes & $27.9(17)$ & $72.1(44)$ & $<0.001$ & $37.1(13)$ & $62.9(22)$ & $<0.001$ \\
\hline No & $74.3(26)$ & $25.7(9)$ & & $3.3(2)$ & $96.7(59)$ & \\
\hline \multicolumn{7}{|c|}{ Referral to dentist } \\
\hline Yes & $25.8(16)$ & $74.2(46)$ & $<0.001$ & $4 I .2(14)$ & $58.8(20)$ & $<0.001$ \\
\hline No & $79.4(27)$ & $20.6(7)$ & & $1.6(\mathrm{I})$ & $98.4(6 \mathrm{I})$ & \\
\hline \multicolumn{7}{|c|}{ Brushing teeth } \\
\hline Every day & $48.9(22)$ & 5I.I (23) & 0.065 & $15.6(7)$ & $84.4(38)$ & 0.048 \\
\hline Sometimes & $35.6(16)$ & $64.4(29)$ & & II.I (5) & $88.9(40)$ & \\
\hline Never & $83.3(5)$ & $16.7(1)$ & & $50.0(3)$ & $50.0(3)$ & \\
\hline
\end{tabular}

family monthly income of $>$ SR 10,000 (OR 18.32, 95\% CI 2.12-158.44; $P=0.008$ ), CP (OR 5.06, 95\% CI 1.28-19.99; $P=0.021$ ), motor disability (OR 6.41, 95\% CI 1.12-36.73; $P=0.037$ ), referral for dental review after coming to the neuropediatric clinic (OR 10.755, 95\% CI 3.290-35.151; $P<0.001$ ), and irregular brushing of teeth (OR 5.397, 95\% CI 1.536-18.961; $P=0.009)$. Perception of the child as being overweight (OR $0.117,95 \%$ CI $0.034-0.400 ; P=0.001$ ) was significantly associated with decreased reporting of bad teeth.

\section{Univariate and multivariate analyses for need of dental care}

Univariate analysis revealed that parents were more likely to report a need for dental care in cases of CP (OR 3.56, 95\% CI 1.14-11.11; $P=0.029$ ), cognitive disability (OR 3.29, 95\% CI $1.05-10.37 ; P=0.042$ ), motor disability (OR 4.64, 95\% CI 1.47-14.70; $P=0.009$ ), previous visit to the dentist (OR $17.432,95 \%$ CI $3.637-83.550 ; P<0.001)$, and referral to a dentist after coming to the neuropediatric clinic (OR 42.70, 95\% CI 5.278-345.457; $P<0.001)$. Perception of child as being overweight by parent (OR 0.057, 95\% CI 0.012-0.275; $P<0.001)$ was significantly associated with decreased per- ceived need for dental care. Under multivariate analysis, only motor disability (OR 5.73, 95\% CI 1.64-20.04; $P=0.006$ ) was significantly associated with increased perceived need for dental care.

\section{Discussion}

Children and adults with epilepsy are frequently seen in dental practice, and the estimated prevalence of epilepsy is $0.9 \%{ }^{13}$ Dental procedures have an innate risk of causing seizures, and as a result dentists should have sufficient background knowledge about the patient's condition and how to manage it, especially since epilepsy is the commonest medical emergency in dental practices. ${ }^{14}$ Our study assessed levels of oral hygiene in children with epilepsy as reported by their mothers.

Our findings suggest that children with CP-related epilepsy had sixfold-higher odds of bad teeth and more than threefold-higher odds of perceived need for dental care than children with noncerebral palsy. This is consistent with other studies reporting a relation between severity of neurological insult in children with $\mathrm{CP}$ and risk of having a dental disease. ${ }^{15,16}$ There are multiple possible contributing etiologies 
to this relationship. One is having difficulties in coordinating movement, which can make as simple a task as brushing one's teeth considerably difficult.

Another factor is the presence of cognitive impairment, where we found that children with cognitive disability had fivefold-higher odds of bad teeth status and threefold-higher odds of perceived need for dental care than children without cognitive impairment. Cognitive disability is seen more frequently in children with severe $\mathrm{CP}$, and is also accompanied with evidence of cortical abnormalities on imaging. ${ }^{17}$ Our finding is supported by evidence presented by Dourado et al, ${ }^{18}$ who found that the risk of having dental caries increases with the severity of intellectual impairment. This is proven to affect negatively the quality of life of patients with $\mathrm{CP} .{ }^{19}$ The main reason seems to be that cognitive disability makes the child's cooperation in brushing and caring for their teeth and oral health more challenging for the parents. ${ }^{20}$ Dependence of care on a caregiver is an independent factor associated with dental disease, especially in patients with $\mathrm{CP}^{21}$

Children with motor disability had more than sevenfoldhigher odds of being reported as having bad teeth and more than fourfold-higher odds of perceived need for dental care than children with no motor disability. The finding is consistent with a study that found malnutrition to be a common finding in patients with $\mathrm{CP}$, which in turn has a negative effect on dental health. ${ }^{22}$

Pseudobulbar palsy also plays a major role in the development of dental disease, due to the loss of coordination in functions related to eating, such as chewing food and swallowing it, in addition to not being able to control salivation, resulting in sialorrhea. ${ }^{23}$ It is worth noting that periodontal disease tends to occur more in patients with spastic quadriplegic $\mathrm{CP} .{ }^{1}$ Abnormalities of oral coordination may even be precipitated by antiepileptic drugs like clonazepam, which may cause aspiration. ${ }^{13}$ Phenytoin, another antiepileptic drug, can cause gingival hyperplasia and consequently lead to periodontal disease as well. Dental erosion is associated with swallowing dysfunction ${ }^{15}$ and gastroesophageal reflux disease, ${ }^{24}$ which is quite common in patients with CP. Care should thus be given to diagnosing them properly.

Patients with CP are also more likely to suffer from repeated acts of teeth clenching or grinding (bruxism), especially if their cognitive or motor disability is severe. ${ }^{25}$ This act leads to considerable damage to dental surfaces, resulting in a flat bite surface. The risk of dental trauma, including facial injury and enamel fractures, is increased in patients with CP-related motor disability and epilepsy. This risk is increased even more in children who have drop attacks, up to $60 \% .{ }^{26}$ Even though our findings suggest that the presence of drop attacks is associated with reporting of good dental status, this is contradictory to most of the literature. More likely are confounding comorbidities, such as the possibility that children with no drop attacks in our studied population may have had severe cognitive or motor disability, possibly skewing the results in one direction.

Children whose family income was >SR10,000 had 18 times the odds of parental concerns of bad teeth than children whose family income was $<$ SR5,000. In addition, lower parent education was associated with reporting of good teeth. These findings are contradictory to studies that have reported higher socioeconomic status to play an important role in better dental care for children with disabilities and thus a tendency to have better teeth. ${ }^{27-29}$ One explanation for such disparity may be due to poor education about what constitutes good dental health. Another explanation could be that families on low incomes may not have the time to give all their attention to their children, and thus they may not be aware of their dental need or status. The mother's opinion or reference of what good dental health is supposed to be like may differ according to socioeconomic status, which can affect the results.

Perception of the child being overweight by their parents was significantly associated with decreased risk of reported bad teeth. This finding can be explained if we correlate it with nutrition status, as underweight children are more likely to have some form of nutrional deficiency, which can affect their dental health negatively. In contrast, children perceived as overweight by their parents were less likely to have malnutrition of some form. This explanation is supported by other research. ${ }^{22}$ Particularly, children with $\mathrm{CP}$ on liquid diets were more likely to develop dental caries than those on solid diets. ${ }^{15}$

Children who had had previous visits to the dentist prior to attending our clinic had seven times the odds of reported bad teeth than children who had not previously had their teeth checked by a dentist. Children who had received a dental appointment (referral) after attending our clinic were at 11 times the odds of bad teeth than children who were not referred to a dentist. Causation cannot be established here, as the children who attended a dentist or needed referral may already have had dental conditions, which explains why they got the referral on their visit. Other studies have reported results opposite to ours, where better overall dental status was associated with routine visits to the dentist. ${ }^{27,28}$

One limitation of this study is that we utilized convenience sampling, and this can introduce sampling bias. Another limitation is differences in parents' perception of 
what the optimal dental status for their child is. A standardized test to assess children accurately by independent dentists should be the focus of future studies; however, that would add considerable cost to the study. Increasing the sample size and demographics by involving all major regions in Saudi Arabia would improve accuracy and give a better picture of the dental status of children with epilepsy in our region. With nearly $85 \%$ of children in need of dental care according to their mothers, dental care should start at home and early in life. Dentists should teach parents how to maintain proper dental hygiene ${ }^{21}$ with correct brushing technique and what to do if they are met with any difficulty or resistance from the child.

\section{Conclusion}

Dental hygiene is not properly maintained in children with epilepsy as reported by the parents, and more so in children with CP. There is a need for dentists' participation in the health-care teams for children with epilepsy, and this should be supplemented by proper training of parents on how to deal with their child's special needs.

\section{Disclosure}

The authors report no conflicts of interest in this work.

\section{References}

1. Jan MM. Clinical review of pediatric epilepsy. Neurosci Riyadh Saudi Arab. 2005;10(4):255-264.

2. Kaeberle J. Epilepsy disorders and treatment modalities. NASN Sch Nurse. 2018;33(6):342-344.

3. Reilly C, Atkinson P, das KB, et al. Neurobehavioral comorbidities in children with active epilepsy: a population-based study. Pediatrics. 2014;133(6):e1586-e1593.

4. Chiang KL, Cheng CY. Prevalence and neuro-psychiatric comorbidities of pediatric epilepsy in Taiwan: a national population-based study. Epilepsy Res. 2014;108(8):1451-1460.

5. Anjomshoaa I, Cooper ME, Vieira AR. Caries is associated with asthma and epilepsy. Eur J Dent. 2009;3(4):297-303.

6. Reid AY, Metcalfe A, Patten SB, Wiebe S, Macrodimitris S, Jetté N. Epilepsy is associated with unmet health care needs compared to the general population despite higher health resource utilization--a Canadian population-based study. Epilepsia. 2012;53(2):291-300.

7. Percival T, Aylett SE, Pool F, Bloch-Zupan A, Roberts GJ, Lucas VS. Oral health of children with intractable epilepsy attending the UK National Centre for Young People with Epilepsy. Eur Arch Paediatr Dent. 2009;10(1):19-24.

8. Gurbuz T, Tan H. Oral health status in epileptic children. Pediatr Int. 2010;52(2):279-283.

9. Ghafoor PA, Rafeeq M, Dubey A. Assessment of oral side effects of antiepileptic drugs and traumatic oro-facial injuries encountered in Epileptic children. J Int Oral Health. 2014;6(2):126-128.
10. Joshi NH, Deshpande AN, Deshpande NC, Rathore AS. Comparative evaluation of oral hygiene status and gingival enlargement among epileptic and healthy children as related to various antiepileptic drugs. J Indian Soc Periodontol. 2017;21(2):125-129.

11. Jan MM. Cerebral palsy: comprehensive review and update. Ann Saudi Med. 2006;26(2):123-132.

12. Grzic R, Bakarcic D, Prpic I. Dental health and dental care in children with cerebral palsy. Coll Antropol. 2011;35:76-764.

13. Mehmet Y, Senem Ö, Sülün T, Hümeyra K. Management of epileptic patients in dentistry. Surgical Science. 2012;13;3(1):47.

14. Chapman PJ. Medical emergencies in dental practice and choice of emergency drugs and equipment: a survey of Australian dentists. Aust Dent J. 1997;42(2):103-108.

15. Santos MT, Guare RO, Celiberti P, Siqueira WL. Caries experience in individuals with cerebral palsy in relation to oromotor dysfunction and dietary consistency. Spec Care Dentist. 2009;29(5):198-203.

16. Jones MW, Morgan E, Shelton JE. Primary care of the child with cerebral palsy: a review of systems (part II). J Pediatr Health Care. 2007;21(4):226-237.

17. Russman BS, Ashwal S. Evaluation of the child with cerebral palsy. Semin Pediatr Neurol. 2004;11(1):47-57.

18. Dourado MR, Andrade PM, Ramos-Jorge ML, Moreira RN, Oliveira-Ferreira F. Association between executive/attentional functions and caries in children with cerebral palsy. Res Dev Disabil. 2013;34(9):2493-2499.

19. Subasi F, Mumcu G, Koksal L, Cimilli H, Bitlis D. Factors affecting oral health habits among children with cerebral palsy: pilot study. Pediatr Int. 2007;49(6):853-857.

20. Jan MM. Neurological examination of difficult and poorly cooperative children. J Child Neurol. 2007;22(10):1209-1213.

21. Ferguson FS, Cinotti D. Home oral health practice: the foundation for desensitization and dental care for special needs. Dent Clin North Am. 2009;53(2):375-387.

22. Eltumi M, Sullivan PB. Nutritional management of the disabled child: the role of percutaneous endoscopic gastrostomy. Dev Med Child Neurol. 1997;39(1):66-68.

23. Siegel LK, Klingbeil MA. Control of drooling with transdermal scopolamine in a child with cerebral palsy. Dev Med Child Neurol. 1991;33(11):1013-1014.

24. Polat Z, Akgun OM, Turan I, Polat GG, Altun C. Evaluation of the relationship between dental erosion and scintigraphically detected gastroesophageal reflux in patients with cerebral palsy. TurkJ Med Sci. 2013;43:283-288.

25. Ortega AO, Guimarães AS, Ciamponi AL, Marie SK. Frequency of parafunctional oral habits in patients with cerebral palsy. JOral Rehabil. 2007;34(5):323-328.

26. Al-Banji MH, Zahr DK, Jan MM. Lennox-Gastaut syndrome. Management update. Neurosciences. 2015;20(3):207-212.

27. Al Agili DE, Roseman J, Pass MA, Thornton JB, Chavers LS. Access to dental care in Alabama for children with special needs: parents' perspectives. J Am Dent Assoc. 2004;135(4):490-495.

28. Finger ST, Jedrychowski JR. Parents' perception of access to dental care for children with handicapping conditions. Spec Care Dentist. 1989;9(6):195-199.

29. Case A, Lubotsky D, Paxson C. Economic status and health in childhood: the origins of the gradient. Am Econ Rev. 2002;92(5):1308-1334. 


\section{Publish your work in this journal}

Pediatric Health, Medicine and Therapeutics is an international, peerreviewed, open access journal publishing original research, reports, editorials, reviews and commentaries. All aspects of health maintenance, preventative measures and disease treatment interventions are addressed within the journal. Practitioners from all disciplines are invited to submit their work as well as healthcare researchers and patient support groups. The manuscript management system is completely online and includes a very quick and fair peer-review system. Visit http://www.dovepress.com/ testimonials.php to read real quotes from published authors.

Submit your manuscript here: http://www.dovepress.com/pediatric-health-medicine-and-therapeutics-journal 